\title{
Inherited Breast Cancer
}

Aphrodite V. Nonni ${ }^{1}$, Niki J. Agnantis ${ }^{1}$, Emmanuel Kontostolis ${ }^{2}$ and Dimitrios Lolis ${ }^{2}$

${ }^{1}$ Pathology Department, University Hospital of the Ioannina Medical School, Ioannina,

Greece

${ }^{2}$ Clinic of Obstetrics and Gynaecology, University Hospital of the Ioannina Medical School, Ioannina, Greece

During an eight-year period (January 1991January 1999) a total of 11,200 women were examined at the breast out-patient Department of the University Hospital.

Of these, 7,750 were registered for the first time and 3,450 repeated their visit for different reasons. Of the 7,750 women, breast cancer was diagnosed in 261, who were treated appropriately. Out of the 261 breast cancer patients 9 (3.44\%) had a family history. We summarise the collected data of these 9 patients in Table 1.

The mean age of these 9 patients is 46 years and the median age 49.2 years. Additionally, the mean time of FU is 47 months and the median time 40.77 months.

Two procedures are ongoing: the immunohistochemical evaluation of the monoclonal antibody BRCA1 (oncogene) and the molecular study of the BRCA1 and BRCA2 germline mutation.

Table 1

\begin{tabular}{|c|c|c|c|c|c|c|c|c|c|c|c|}
\hline $\begin{array}{l}\text { Pt. } \\
\text { no. }\end{array}$ & Age & $\begin{array}{l}\text { T. size } \\
\text { in } \mathrm{cm} \text {. }\end{array}$ & $\begin{array}{l}\text { T. Histo- } \\
\text { type }\end{array}$ & T. Grade & L. Inf. & ER* & PgR* & LNM & FU in months & $\begin{array}{l}\text { Relatives with } \\
\text { BC }\end{array}$ & $\begin{array}{l}\text { Age } \mathrm{D} / \mathrm{S} \text { and } \\
\text { FU of relatives }\end{array}$ \\
\hline 1 & 64 & 2.5 & ID. NST & II & - & $\begin{array}{l}50 \% \\
(++)\end{array}$ & $\begin{array}{l}40 \% \\
(++)\end{array}$ & $0 / 4$ & $51 \mathrm{NED}$ & 1 sister & $\begin{array}{l}36 \mathrm{D} / \mathrm{S} \\
39 \mathrm{died}\end{array}$ \\
\hline 2 & 46 & 3 & $\begin{array}{l}\text { DCIS all } \\
\text { types }\end{array}$ & III N.Gr. & - & $\begin{array}{c}60 \% \\
(+)\end{array}$ & $\begin{array}{l}>75 \% \\
(+++)\end{array}$ & $0 / 8$ & 26 NED & Mother & $\begin{array}{l}73 \mathrm{D} / \mathrm{S} \\
75 \mathrm{died}\end{array}$ \\
\hline 3 & 28 & 4 & ID. NST & III & - & $\begin{array}{l}0 \% \\
(-)\end{array}$ & $\begin{array}{l}0 \% \\
(-)\end{array}$ & $+1 / 12$ & 12 NED & Mother & $\begin{array}{l}39 \mathrm{D} / \mathrm{S} \\
42 \mathrm{died}\end{array}$ \\
\hline 4 & 40 & 1.9 & ID. NST & II & + & $\begin{array}{l}55 \% \\
(++)\end{array}$ & $\begin{array}{c}50 \% \\
(+)\end{array}$ & $0 / 10$ & 52 NED & $\begin{array}{c}\text { Mother's sister } \\
1 \text { sister }\end{array}$ & $\begin{array}{c}36 \mathrm{D} / \mathrm{S} \\
40 \mathrm{died} \\
42 \mathrm{D} / \mathrm{S} \\
47 \mathrm{NED}\end{array}$ \\
\hline 5 & 45 & 4.5 & IL & III & - & $\begin{array}{l}40 \% \\
(++)\end{array}$ & $\begin{array}{c}<25 \% \\
(-)\end{array}$ & $+1 / 36$ & 81.5 NED & Mother & $\begin{array}{l}35 \mathrm{D} / \mathrm{S} \\
39 \mathrm{died}\end{array}$ \\
\hline 6 & 47 & 4 & $\begin{array}{l}\text { DCIS } \\
\text { comedo }\end{array}$ & III N.Gr. & - & $\begin{array}{l}0 \% \\
(-)\end{array}$ & $\begin{array}{l}0 \% \\
(-)\end{array}$ & $0 / 13$ & 11 NED & Mother & $\begin{array}{l}50 \mathrm{D} / \mathrm{S} \\
54 \mathrm{died}\end{array}$ \\
\hline 7 & 67 & 3 & Mucinous & II & - & $\begin{array}{l}60 \% \\
(++)\end{array}$ & $\begin{array}{l}80 \% \\
(++)\end{array}$ & $+1 / 6$ & 16 NED & Mother & $\begin{array}{l}61 \mathrm{D} / \mathrm{S} \\
65 \mathrm{died}\end{array}$ \\
\hline 8 & 40 & 3 & $\begin{array}{l}\text { Mixed } \\
\text { ID+IL }\end{array}$ & II & - & $0 \%$ & $\begin{array}{l}0 \% \\
(-)\end{array}$ & $0 / 4$ & 57.5 NED & $\begin{array}{l}\text { Mother } \\
1 \text { sister }\end{array}$ & $\begin{array}{c}79 \mathrm{D} / \mathrm{S} \\
83 \mathrm{died} \\
46 \mathrm{D} / \mathrm{S} \\
53 \mathrm{NED}\end{array}$ \\
\hline 9 & 66 & 4 & ID. NST & II & +++ & $\begin{aligned}< & 25 \% \\
& (-)\end{aligned}$ & $\begin{array}{c}\sim 30 \% \\
(+)\end{array}$ & $\begin{array}{l}+3 \mathrm{LN} \\
\text { block }\end{array}$ & 47 NED & 1 sister & $\begin{array}{l}54 \mathrm{D} / \mathrm{S} \\
55 \mathrm{died}\end{array}$ \\
\hline
\end{tabular}

* Evaluated immunohistochemically; Key to abbreviations: Pt. = patient, T. = tumour, N.Gr. = Nuclear Grade, L.Inf. $=$ Lymphocytic Infiltration, ER = Estrogen Receptor, PgR = Progesterone Receptor, LNM $=$ Lymph node metastases, $\mathrm{FU}=$ Follow-up, $\mathrm{D} / \mathrm{S}=$ Diagnosis, ID. NST = Invasive ductal, no special type, DCIS = Ductal carcinoma in situ, IL = Infiltrating lobular, NED $=$ No evidence of disease. 


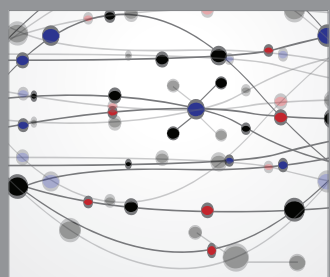

The Scientific World Journal
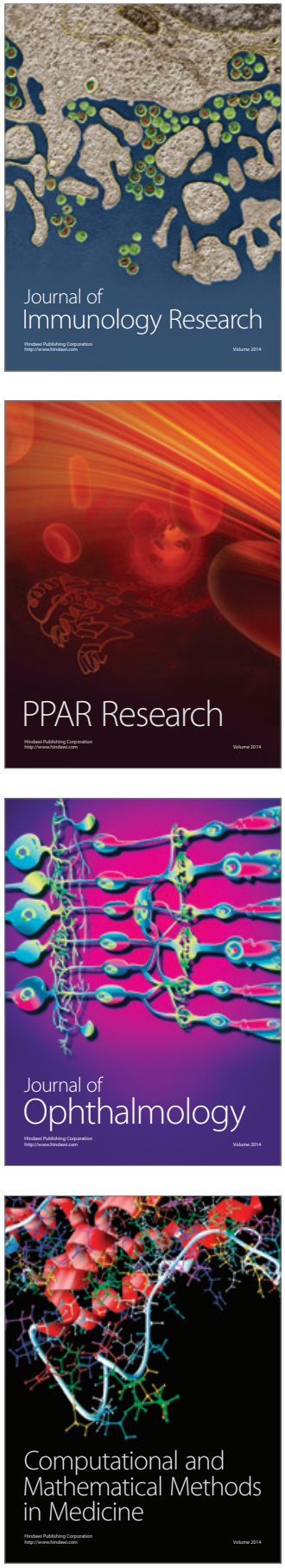

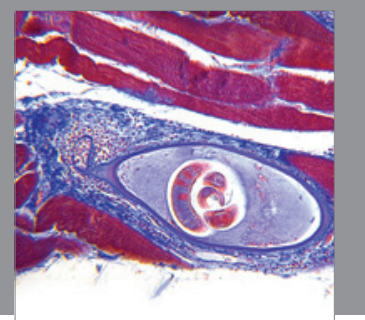

Gastroenterology

Research and Practice
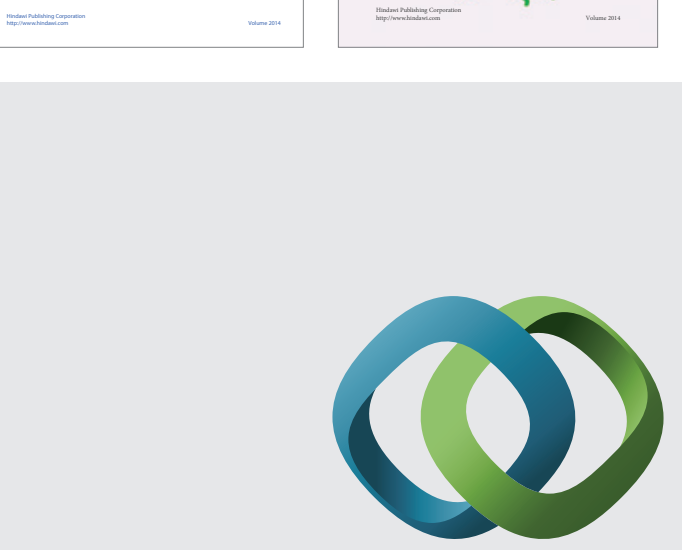

\section{Hindawi}

Submit your manuscripts at

http://www.hindawi.com
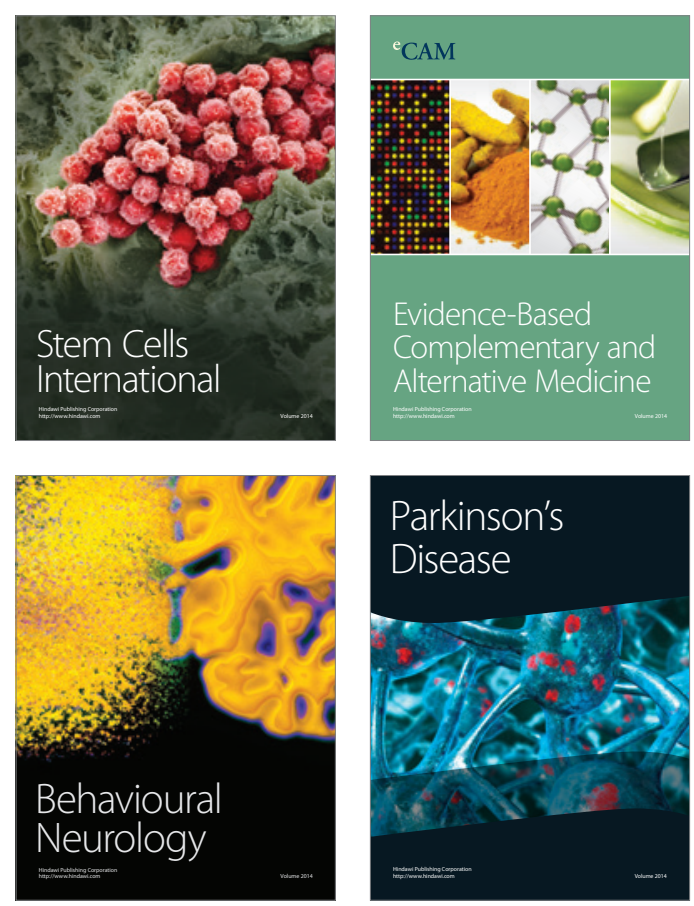

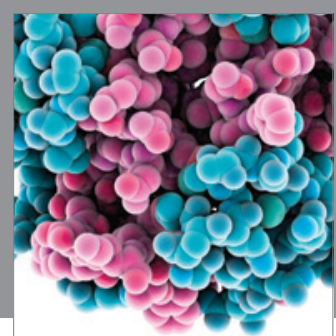

Journal of
Diabetes Research

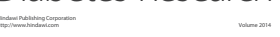

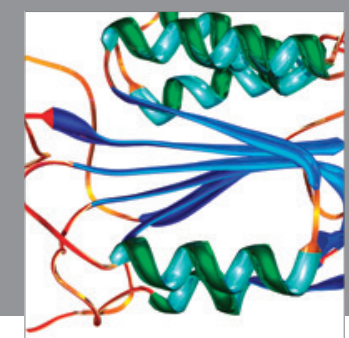

Disease Markers
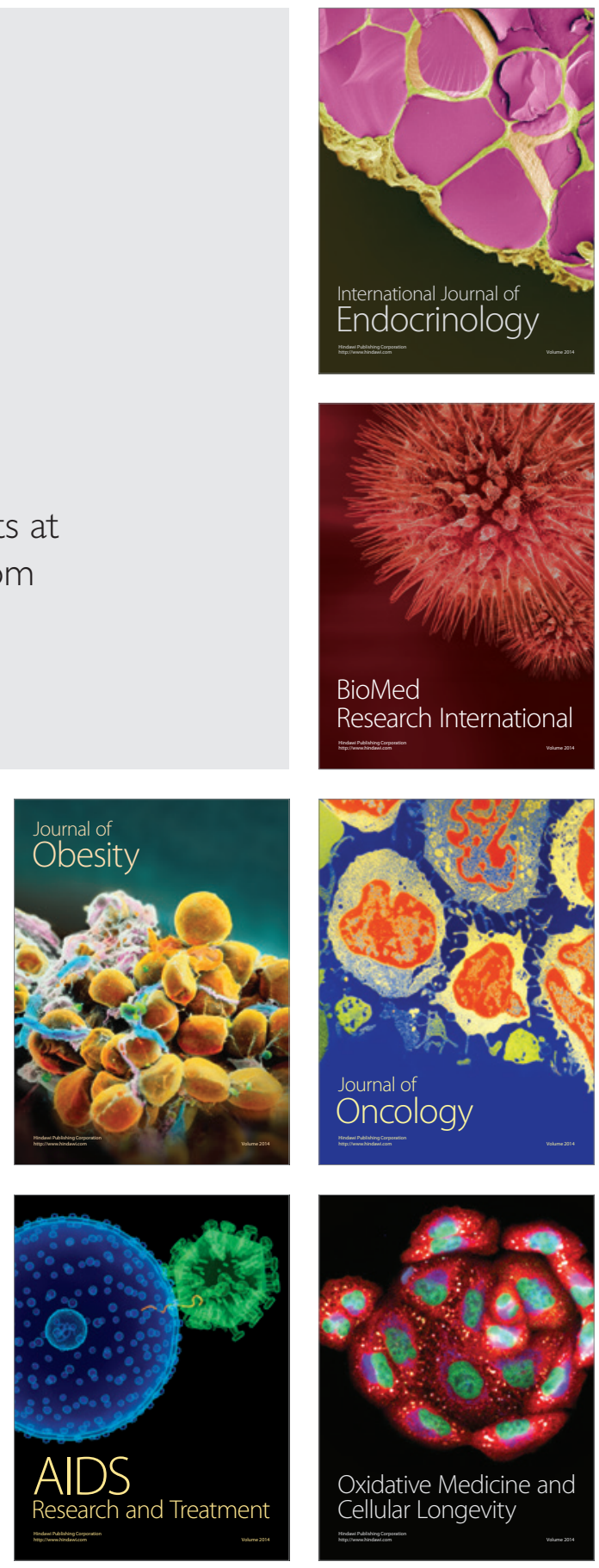